
\title{
CIÊNCIANATURA
}

\section{Distribuição Espaço Temporal Da Precipitação Pluvial E Sua Interação Com O Relevo Na Bacia Do Rio Jacaré Guaçu (SP)}

Temporal and spatial distribution of rainfall and interaction with relief in Jacaré Guaçú watershed (São Paulo State - Brazil)

\author{
Vladimir Souza ${ }^{1}$ e Emerson Galvani ${ }^{2}$ \\ ${ }^{1}$ Universidade de São Paulo, São Paulo, Brasil \\ vladimirsouza@usp.br \\ ${ }^{2}$ Universidade de São Paulo, São Paulo, Brasil \\ egalvani@usp.br
}

\section{Resumo}

O presente estudo teve como objetivo determinar a variabilidade temporal e espacial da precipitação pluvial e avaliar a influência do relevo como potencializador do efeito orográfico das chuvas na bacia do rio Jacaré Guaçú, localizada no interior do estado de São Paulo. Dados pluviométricos, topográficos, análise estatística e técnicas de Geoprocessamento foram usadas para atingir os objetivos propostos. Os resultados demonstram que a precipitação média anual na bacia varia entre 1313 e $1680 \mathrm{~mm}$. Os menores valores estão dispostos nos setores oeste, noroeste e sudeste da bacia hidrográfica e os maiores a leste, no alto Jacaré Guaçú. Para o período sazonal os valores médios variam entre 1082 e $1329 \mathrm{~mm}$ no período chuvoso (outubro a março) e 301 e $364 \mathrm{~mm}$ no menos chuvoso (setembro a abril). A distribuição espacial dos dados sazonais é semelhante a do período anual. O relevo demonstrou exercer influência para a variabilidade de precipitação pluvial na bacia hidrográfica. O gradiente de acréscimo pluviométrico é de 0,8 mm por metro de altitude no sentido oeste para leste, 1,1 mm de noroeste para sudeste e 1,6 mm de norte para sul. Os resultados podem auxiliar na gestão dos recursos hídricos dos municípios que compõem a bacia hidrográfica.

Palavras-chave: Precipitação pluviométrica, efeito orográfico, bacia hidrográfica.

\section{Abstract}

This paper aims to determine the temporal and spatial variability of rainfall and evaluate the influence of the orography over the precipitation in Jacaré Guaçú watershed (São Paulo State - Brazil). Rainfall and topographic data, statistical analysis and Geoprocessing techniques were used to elaborate this research. The results show that the yearly average rainfall in watershed varies between 1313 and $1680 \mathrm{~mm}$. The lowest values of yearly average rainfall are located in the west, northwest and southeast of study area and in the east are the highest values. For the rainy season (October to March) the average rainfall varies between 1082 to $1329 \mathrm{~mm}$. In the less rainy season (September to April) the values vary of 301 to $364 \mathrm{~mm}$. The spatial distribution data of rainy season and less rainy season is similar to the annual period. The relief showed to influence the variability of rainfall in hydrographic basin. The rainfall increase gradient is the $0.8 \mathrm{~mm}$ for each meter of elevation from west to east, $1.1 \mathrm{~mm}$ from northwest to southeast and $1.6 \mathrm{~mm}$ from north to south. The results can contribute to water resource management in the counties of Jacaré Guaçú watershed.

Keywords: Rainfall, Orographic effect, watershed. 


\section{Introdução}

Em bacias hidrográficas localizadas nas regiões tropicais e subtropicais a precipitação pluvial constitui um relevante componente do ciclo hidrológico tendo em vista que, dentre outros fatores, esse evento é responsável pela entrada de água no sistema e que irá condicionar os processos físicos, químicos e biológicos dos elementos que compõem essa unidade de paisagem (GREGORY, WALLING 1973; BERTONI, TUCCI, 2001; PINTO et al. 2014).

Algumas bacias hidrográficas podem apresentar variabilidade espacial e temporal de precipitação pluviométrica. Isso ocorre, sobretudo, devido a sua dimensão espacial, aos aspectos relacionados à topografia (variação de altitude), a localização da área perante as fontes de umidade, ao posicionamento latitudinal geográfico da bacia e a influência de sistemas atmosféricos produtores de tempo (SANTOS et. al. 2011).

A determinação e compreensão desse dinamismo espacial da pluviosidade e de seus fatores são importantes, uma vez que pode contribuir para a gestão dos recursos hídricos, para o entendimento do ciclo hidrológico e para o planejamento urbano e agropecuário das bacias hidrográficas.

Normalmente, a determinação da distribuição espacial da precipitação pluvial ocorre por meio de coleta e análise estatística descritiva de séries temporais de dados obtidos em diferentes postos pluviométricos na bacia hidrográfica e, eventualmente, também em seu entorno. $\mathrm{Na}$ sequência, através da aplicação de algoritmos geoestatísticos em ambiente SIG (Sistema de Informação Geográfica) faz se a interpolação dos dados e o fatiamento de intervalos de interesse para a representação espacial. Informações sobre os aspectos geomorfológicos, de uso e ocupação das terras e do dinamismo sazonal atmosférico da área de estudo podem ser usadas para a compreensão e análise dos resultados alcançados.

No Brasil diversos trabalhos dessa natureza podem encontrados na literatura, a saber: Zavattini e Cano (1993) na bacia do rio Corumbataí (SP), Andrade e Nery (2011) na bacia do rio Ivaí (PR), Santos et. al. (2011) em uma bacia hidrográfica no Estado de Goiás, Zandonadi et. al. (2015) na bacia do rio Paraná e Correa e Galvani (2017) na bacia hidrográfica do rio Piquiri (PR).

Diante dessa contextualização, surgiu o interesse em desenvolver um estudo sobre a variabilidade espacial e temporal da precipitação pluvial na bacia do rio Jacaré Guaçú, localizada na região central do Estado de São Paulo. A bacia pertence à Unidade Hidrográfica de Gerenciamento de Recursos Hídricos do Estado de São Paulo Tietê Jacaré (UGRHI 16) e seus recursos naturais, sobretudo os hídricos, são fundamentais para o desenvolvimento das atividades econômicas e para o abastecimento urbano de boa parte dos municípios que a integram (SIGRH, 2017).

Para o desenvolvimento do trabalho, além de dados pluviométricos, da análise estatística e das técnicas de Geoprocessamento foram usadas informações topográficas para verificar a influência do relevo como potencializador do efeito orográfico para a pluviosidade na área de estudo, cuja amplitude altimétrica é de $680 \mathrm{~m}$ (USGS, 2016). Basicamente, o relevo pode atuar como uma barreira durante o processo de deslocamento de uma parcela de ar que contenha determinado teor de umidade (CANDIDO, NUNES, 2008). Com a ascensão dessa porção de ar úmido sobre uma feição geomórfica relativamente elevada, ocorrerá o resfriamento adiabático e, eventualmente, a condensação da umidade, a formação de nuvens e a precipitação. Com isso, um dinamismo no montante pluvial em áreas relativamente próximas com altitudes diferentes poderá ocorrer.

Portanto, o presente estudo teve como objetivo determinar a variabilidade temporal e espacial da precipitação pluviométrica e avaliar de forma quantitativa a influência do relevo como potencializador do efeito orográfico das chuvas na bacia do rio Jacaré Guaçú. 


\section{1. Área de estudo}

Localizada no interior do Estado de São Paulo, sudeste do Brasil, a bacia do rio Jacaré Guaçú ocupa uma área aproximada de $4057 \mathrm{~km}^{2}$ a margem direita do rio Tietê. Os municípios de Nova Europa e Gavião Peixoto ocupam totalmente a bacia hidrográfica enquanto que São Carlos, Brotas, Analândia, Ribeirão Bonito, Araraquara, Ibaté, Matão, Ibitinga, Itirapina, Tabatinga, Trabiju, Dourado e Boa Esperança do Sul apresentam ocupação parcial da área de estudo (Figura 1).

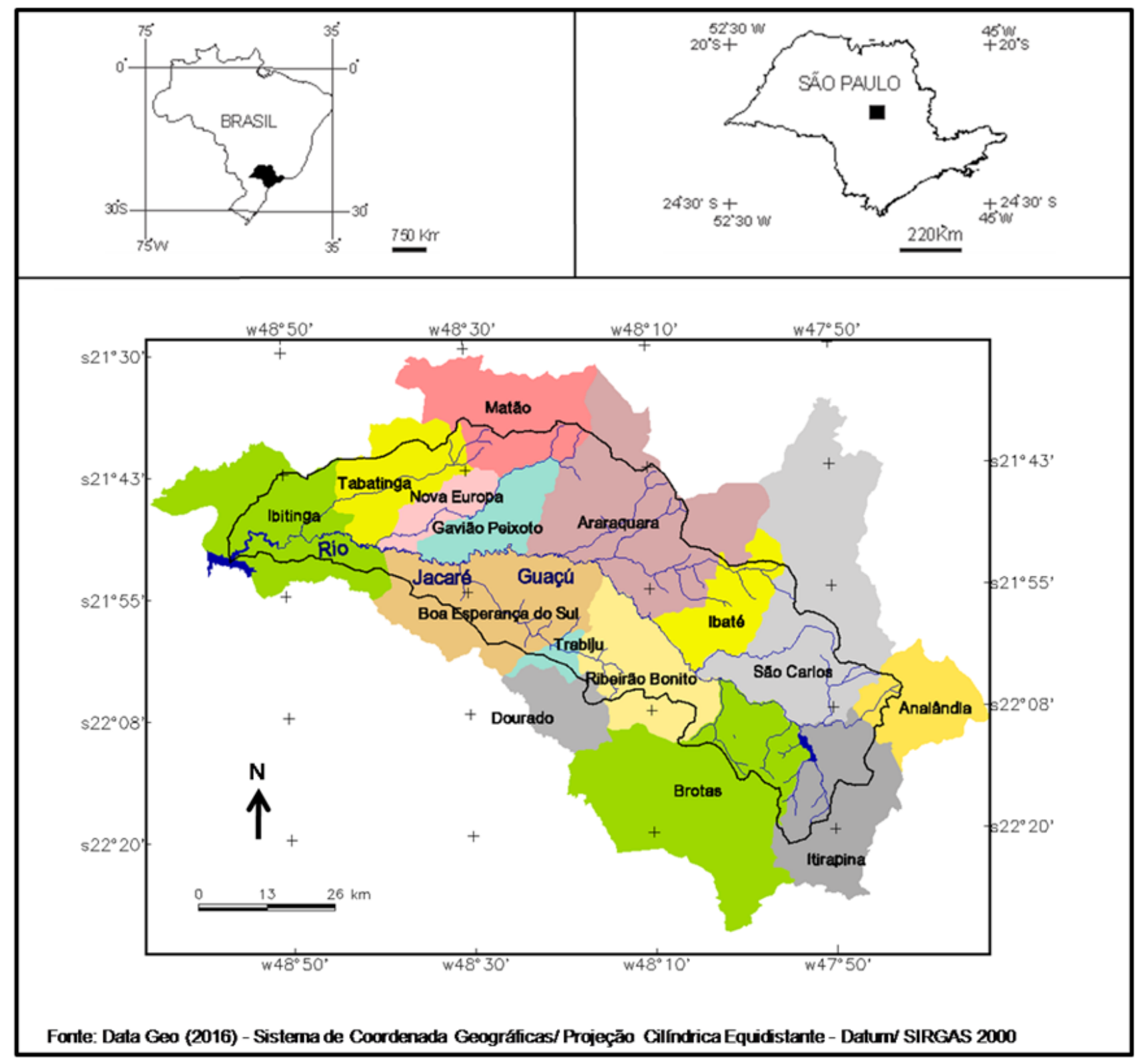

Figura 1-Localização da área de estudo.

A bacia hidrográfica está estruturada por rochas vulcânicas e sedimentares da bacia Fanerozóica do Paraná que, em termos morfoesculturais, apresenta localidades dispostas no Planalto Ocidental Paulista, especificamente nas subunidades Planalto Residual de São Carlos e Planalto Centro Ocidental (ROSS, MOROZ, 1997; PERROTA et. al., 
2005). Em função dos aspectos físiográficos predominam na área de estudo solos de textura e estrutura variada, com destaque para Latossolos, Argissolos, Neossolos, Gleissolos, Planossolos e Organossolos (OLIVEIRA, 1999).

Monteiro (1973) classifica como tropical alternadamente seco e úmido o clima da região onde está inserida a bacia hidrográfica. De acordo com o autor, além da influência geomórfica da serra de São Carlos, sistemas atmosféricos de origem tropical e equatorial controlam o clima da região central paulista. Nesse sentido, são verificados totais pluviométricos que variam entre 1500 e 2.000 mm no Planalto Residual de São Carlos e 1100 e 1500 mm no Planalto Centro Ocidental com concentração do período chuvoso de outubro a março e menos chuvoso entre abril e setembro (SANT'ANNA NETO, 1995).

Para o IBGE (2002) a temperatura média do mês mais frio na região central do Estado de São Paulo varia entre $15^{\circ} \mathrm{C}$ e $18^{\circ} \mathrm{C}$ enquanto que no mês mais quente são verificados valores acima de $22^{\circ} \mathrm{C}$. Uma pequena variação dessas médias térmicas pode ocorrer em função das diferenças altimétricas dispostas nos variados compartimentos geomorfológicos da região.

Em termos fitogeográficos a bacia do rio Jacaré Guaçú apresenta ocupação remanescente da Savana (Cerrado) e da Floresta Estacional Semidecidual (IBGE, 1992).

Em termos econômicos na área de estudo são desenvolvidas atividades do setor primário (plantio de cana de açúcar, silvicultura, laranja e pecuária bovina) secundário, (polos industriais de Araraquara e São Carlos) e terciário (atividades comerciais nas áreas urbanas dos municípios). Boa parte dos municípios que compõem a bacia, cuja população estimada foi de 516912 habitantes (IBGE, 2017), utiliza os recursos hídricos para essas atividades econômicas e para o abastecimento de suas áreas urbanas.

\section{Materiais e Métodos}

Para o desenvolvimento do trabalho, inicialmente, foram determinados os valores médios mensais e anuais de 16 postos pluviométricos dispostos na bacia e em seu entorno. Foi considerada ainda, a média de dois períodos: 1Período chuvoso (outubro e março); 2 - Período menos chuvoso (abril a setembro).

A série de dados está compreendida entre os anos de 1968 e 1998 e foi obtida junto ao banco de dados hidrometereológicos do Sistema de Informações para o Gerenciamento de Recursos Hídricos do Estado de São Paulo (SIGRH, 2013) no site http://www.hidrologia.daee.sp.gov.br/.

O método da média aritmética proposto por Bertoni e Tucci (1993) foi usado para preencher eventuais falhas encontradas na série de dados de alguns postos pluviométricos. Para determinar a área de influência dos postos pluviométricos sobre a bacia hidrográfica utilizou-se a proposta da Organização Meteorológica Mundial (WMO, 1994). De acordo com a OMM, o raio de abrangência de um posto pluviométrico em áreas continentais é de $13,5 \mathrm{~km}^{2}$. $\mathrm{Na}$ Figura 2 pode se observar a distribuição postos pluviométricos na área de estudo e em seu entorno, identificados pelo ponto vermelho e com seus respectivos prefixos do Departamento de Águas e Energia Elétrica (DAEE). A área de influência é representada pela cor cinza que corresponde a 83,2\% do total da área da bacia do rio Jacaré Guaçú. 


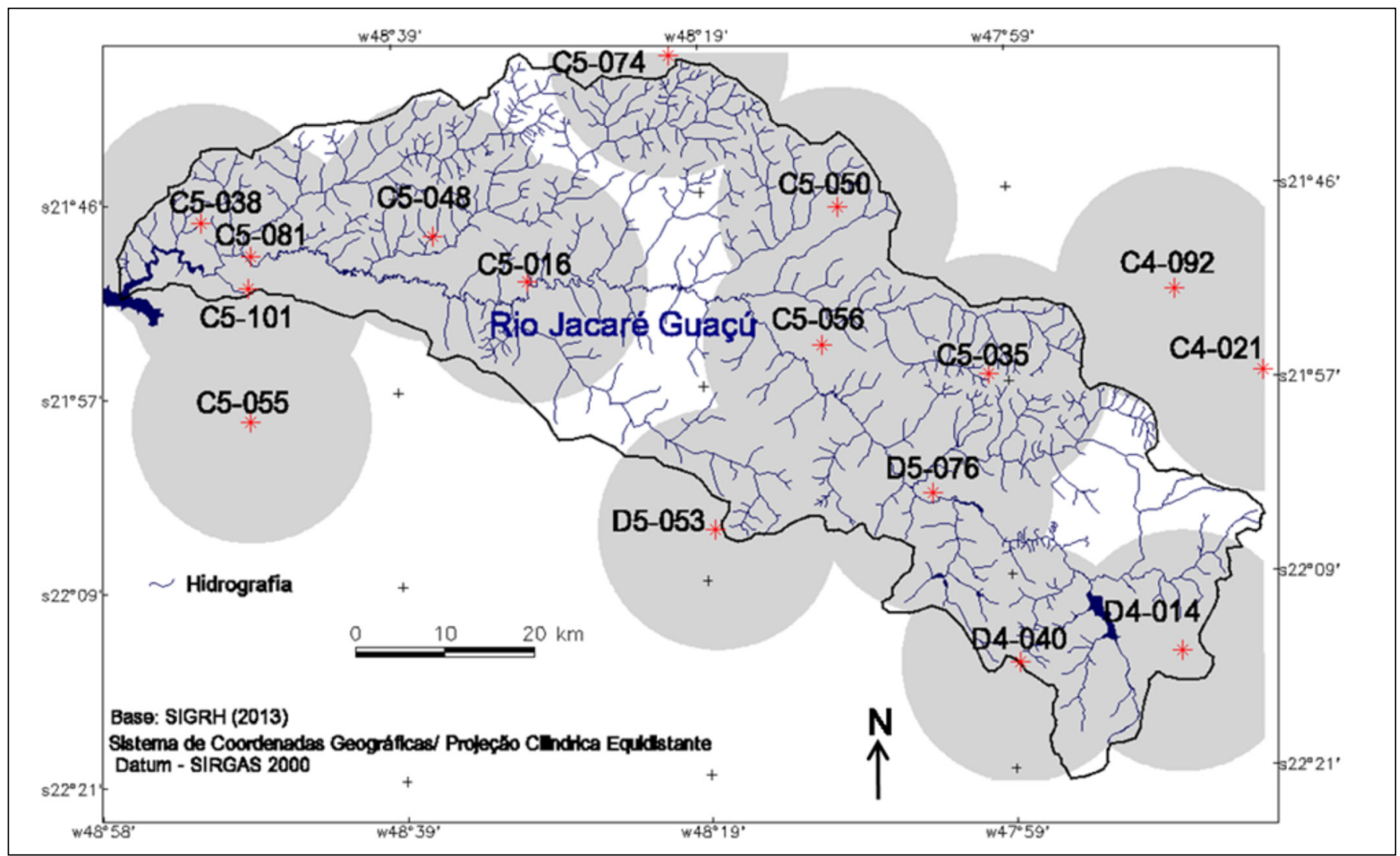

Figura 2- Localização dos postos pluviométricos e suas respectivas abrangências areal na bacia do rio Jacaré Guaçú.

Para a espacialização dos dados anuais e dos dois períodos (chuvoso e menos chuvoso) foi usado o Sistema de Informação Geográfica (SIG) SPRING 5.2.7 (CAMARA et al., 1996). Após atribuir o valor médio de precipitação pluvial para cada ponto digitalizado (posto pluviométrico) na ferramenta de edição vetorial da categoria MNT (Modelo Numérico do Terreno) do SIG executou-se a interpolação dos dados por meio do algoritmo Média Ponderada por Quadrante. Com isso, uma grade espacial numérica com resolução de 30m para X e Y com valores de precipitação pluviométrica foi gerada para a área de estudo. Por fim, os dados numéricos foram agrupados em categorias e transformados em temáticos.

Com intuito de verificar a influência do relevo sobre a distribuição espacial das chuvas na área de estudo foram elaborados três perfis topográficos com base nos dados da missão espacial SRTM. Nos perfis, com orientação oesteleste, noroeste- sudeste e norte -sul, foram plotados sobre os pontos de localização dos postos pluviais os histogramas com os valores de precipitação. Para a elaboração dos transectos foram usadas quatro cenas do sensor para a cobertura total da área de estudo que foram compiladas do site http://earthexplorer.usgs.gov/. Os dados possuem 1 arco de segundo com resolução espacial aproximada de $30 \mathrm{~m}$ (Figura 3). 


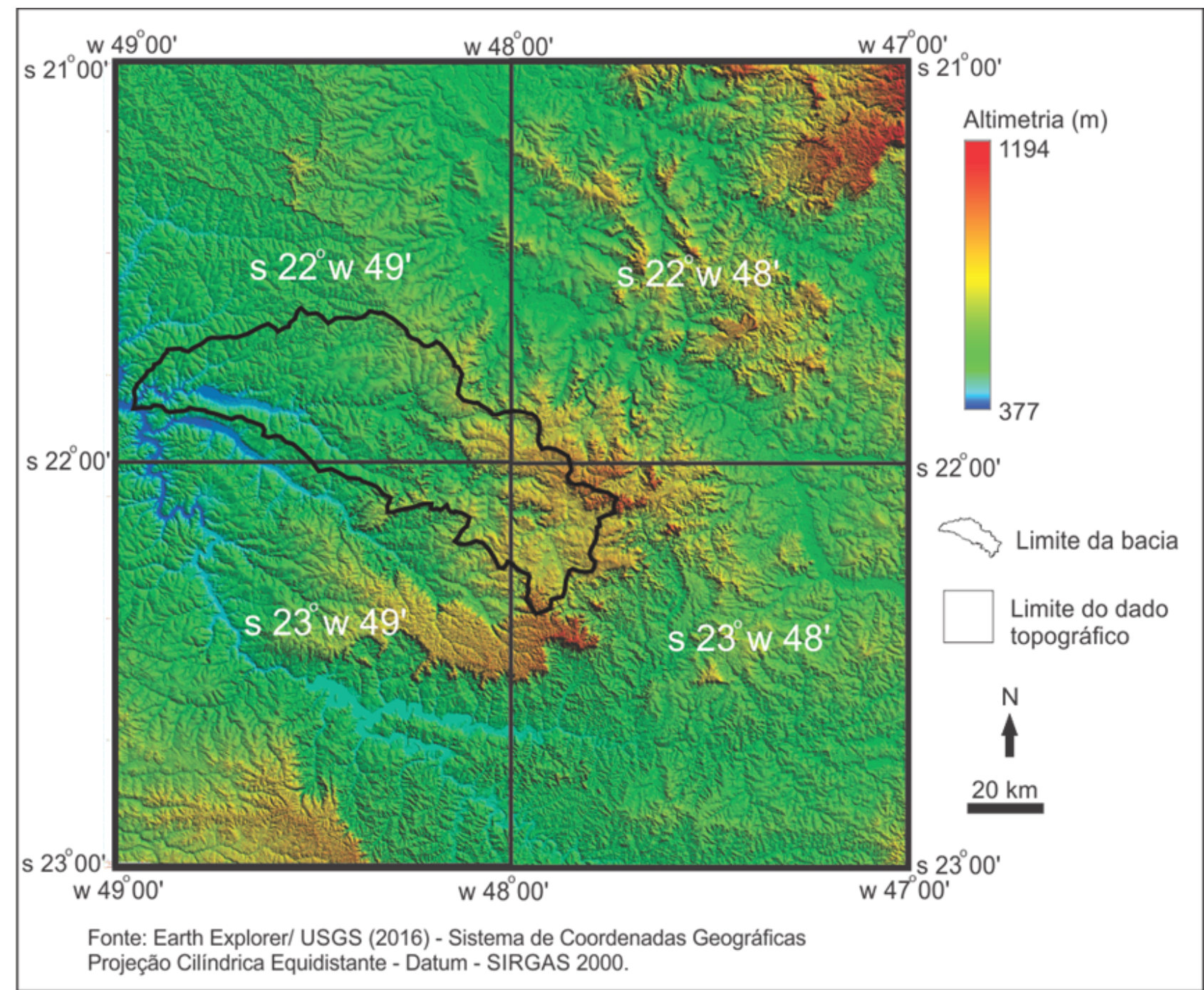

Figura 3-Articulação das folhas com os dados SRTM (representadas com suas respectivas coordenadas geográficas em branco no centro) usadas para análise topográfica na área de estudo.

Por fim, os dados topográficos e pluviais foram apresentados de forma gráfica em duplo eixo "Y" contendo de um lado a variação da altitude e de outro os totais acumulados de precipitação. Na representação gráfica será considerado período chuvoso o acumulado entre os meses de outubro a março e o período menos chuvoso, os totais pluviométricos acumulados entre os meses de abril a setembro.

\section{Resultados e Discussões}

\subsection{Quantificação e espacialização da precipitação pluvial}

A tabela 1 demonstra a identificação, prefixo DAEE, altitude, precipitação média anual e dos períodos considerado chuvoso e menos chuvoso de cada do posto pluviométrico presente na área de estudo e em seu entorno. 
Tabela 1 - Identificação, prefixo DAEE, altitude, média anual de precipitação dos períodos chuvoso e menos chuvoso da bacia do rio Jacaré Guaçú e de seu entorno.

\begin{tabular}{c|c|c|c|c}
\hline $\begin{array}{c}\text { Identificação/ } \\
\text { Prefixo DAEE }\end{array}$ & Altitude(m) & $\begin{array}{c}\text { Precipitação Média /Período } \\
\text { chuvoso }(\mathrm{mm})\end{array}$ & $\begin{array}{c}\text { Precipitação Média /Período } \\
\text { menos chuvoso }(\mathrm{mm})\end{array}$ & $\begin{array}{c}\text { Precipitação Média } \\
\text { Anual }(\mathrm{mm})\end{array}$ \\
\hline 1 - D4-014 & 790 & 1103,4 & 338,0 & 1441,4 \\
\hline 2 - D4 - 040 & 780 & 1000,4 & 313,3 & 1313,7 \\
\hline $3-\mathrm{D} 5-076$ & 580 & 1219,1 & 354,7 & 1573,8 \\
\hline $4-\mathrm{D} 5-053$ & 690 & 1207,5 & 356,5 & 1564,0 \\
\hline $5-\mathrm{C} 4-021$ & 840 & 1329,6 & 350,7 & 1680,3 \\
\hline $6-\mathrm{C} 4-092$ & 610 & 1224,4 & 318,6 & 1543,2 \\
\hline $7-\mathrm{C} 5-074$ & 560 & 1073,6 & 281,2 & 1354,8 \\
\hline $8-\mathrm{C} 5-035$ & 830 & 1291,8 & 364,3 & 1656,1 \\
\hline $9-\mathrm{C} 5-101$ & 490 & 1066,3 & 327,7 & 1394,0 \\
\hline $10-\mathrm{C} 5-038$ & 510 & 1037,8 & 293,5 & 1331,3 \\
\hline $11-\mathrm{C} 5-081$ & 420 & 1031,6 & 323,2 & 1354,8 \\
\hline $12-\mathrm{C} 5-048$ & 490 & 1073,8 & 311,3 & 1385,1 \\
\hline $13-\mathrm{C} 5-016$ & 480 & 1129,9 & 323,9 & 1453,8 \\
\hline $14-\mathrm{C} 5-050$ & 670 & 1193,8 & 317,3 & 1511,1 \\
\hline $15-\mathrm{C} 5-056$ & 560 & 1226,1 & 340,6 & 1566,7 \\
\hline $16-\mathrm{C} 5-055$ & 500 & 1061,5 & 328,4 & 1389,9 \\
\hline
\end{tabular}

É possível observar que o posto 5 (C4-021) apresenta a maior precipitação pluvial média anual (1680,3 mm) e do período considerado como chuvoso $(1329,6 \mathrm{~mm})$. No entanto, nesse mesmo posto o valor de pluviosidade do período menos chuvoso $(350,7 \mathrm{~mm})$ não aparece entre os três maiores. O posto 8 (C5-035) possui maior média do período considerado menos chuvoso $(364,3 \mathrm{~mm})$, a segunda maior média de precipitação pluviométrica anual $(1656,1 \mathrm{~mm}) \mathrm{e}$ também do período chuvoso (1291,8 $\mathrm{mm})$.

Em relação aos menores valores de precipitação pluvial é possível observar que a menor média anual e também do período chuvoso ocorre no posto 2 (D4-040) com valores de 1313,7 mm e 1000,4 mm, respectivamente. Apesar disso, a média do período menos chuvoso desse posto pluviométrico não aparece entre as três menores. $O$ menor valor desse período (menos chuvoso) é encontrado no posto 7 (C5-O74) com 281,2 mm. O posto 10 (C5-038) possui a segunda menor média anual $(1331,3 \mathrm{~mm})$ e do período menos chuvoso $(293,5 \mathrm{~mm})$. Esse posto apresenta ainda, a terceira menor média do período chuvoso (1037,8 mm), atrás do posto 2 (D4-040) como citado e do posto 11 (C5-081) cujo valor é de $1031,6 \mathrm{~mm}$.

A figura 4 demonstra a distribuição espacial da precipitação pluvial média anual na bacia do rio jacaré Guaçú. 


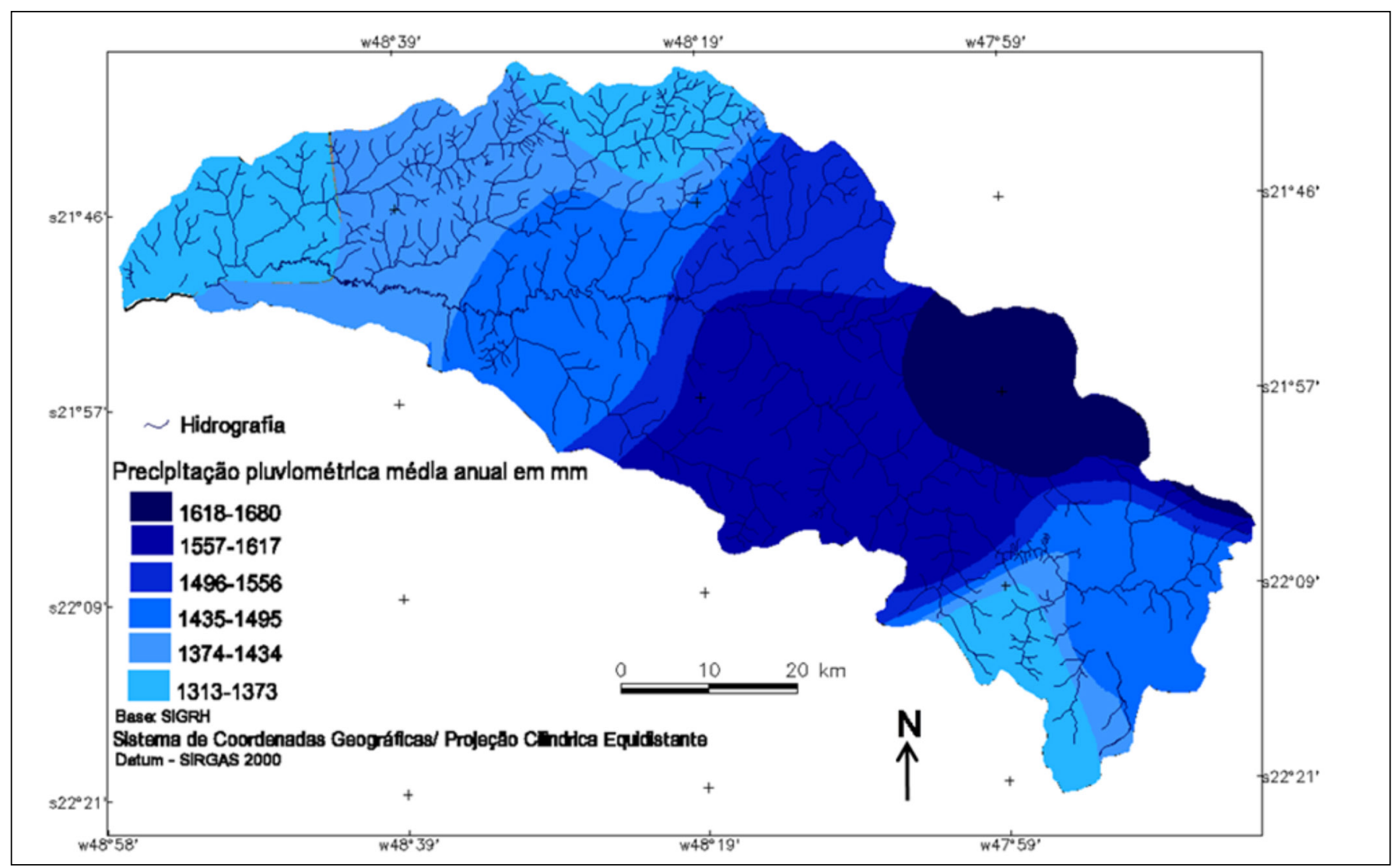

Figura 4 - Distribuição espacial da precipitação pluviométrica anual na área de estudo.

A área ocupada pelas categorias de precipitação anual, determinadas para a área de estudo, pode ser verificada na tabela 2 .

Tabela2 - Área ocupada pelas classes de precipitação pluvial anual na bacia do rio Jacaré Guaçú.

\begin{tabular}{c|r|r}
\hline Categoria em mm & Área em $\mathrm{km}^{2}$ & Porcentagem (\%) \\
\hline $1618-1680$ & 339,1 & 8,3 \\
\hline $1557-1617$ & 966,4 & 23,8 \\
\hline $1496-1556$ & 487,6 & 12,0 \\
\hline $1435-1495$ & 893,3 & 22,1 \\
\hline $1374-1434$ & 679,5 & 16,8 \\
\hline $1313-1373$ & 691,1 & 17,0 \\
\hline Total & 4057,0 & 100,0 \\
\hline \multicolumn{3}{|c}{}
\end{tabular}

Por meio dos dados (Figura 4 e Tabela 2) é possível verificar que os maiores valores (1618-1680 mm) estão dispostos no leste da área de estudo e possuem a menor representatividade de $339,1 \mathrm{~km}^{2}$ (8,3\% da área total da bacia). No centro e sul da bacia hidrográfica, com a maior representação espacial $\left(966,4 \mathrm{~km}^{2}-23,8 \%\right.$ do total da área), aparece o intervalo compreendido entre 1557 e $1617 \mathrm{~mm}$. A terceira categoria (1496-1556 mm) ocorre no médio curso da bacia, no setor norte e ocupa uma área de $487,6 \mathrm{~km}^{2}$, ou seja, $12 \%$ do total da área de estudo. Os valores dispostos entre 1435 e 1495 ocorrem tanto no oeste quanto no sudeste da bacia hidrográfica. Essa classe é a que apresenta a segunda maior representatividade com 22,1\% $\left(893,3 \mathrm{~km}^{2}\right)$ da área de estudo. As categorias 1374-1434 e 1313-1373 ocorrem tanto alto 
quanto no baixo curso do rio Jacaré Guaçú. Em termos de área, a ocupação espacial dessas classes é semelhante, ou seja, $679,5 \mathrm{~km}^{2}\left(16,8 \%\right.$ do total) para a primeira e $691,1 \mathrm{~km}^{2}(17 \%)$ para a segunda.

A precipitação média anual dos 16 postos analisados é de 1469,6 mm. São dados semelhantes aos determinados por Santanna Neto (1995) para a região central do Estado paulista. Na bacia hidrográfica esse valor ocorre dentro da categoria estipulada entre 1435 e $1495 \mathrm{~mm}$ e possui a segunda maior representatividade em termos espaciais conforme observado na Tabela 2 .

Em relação ao período considerado como menos chuvoso (abril a setembro) a espacialização dos dados é apresentada na figura 5.

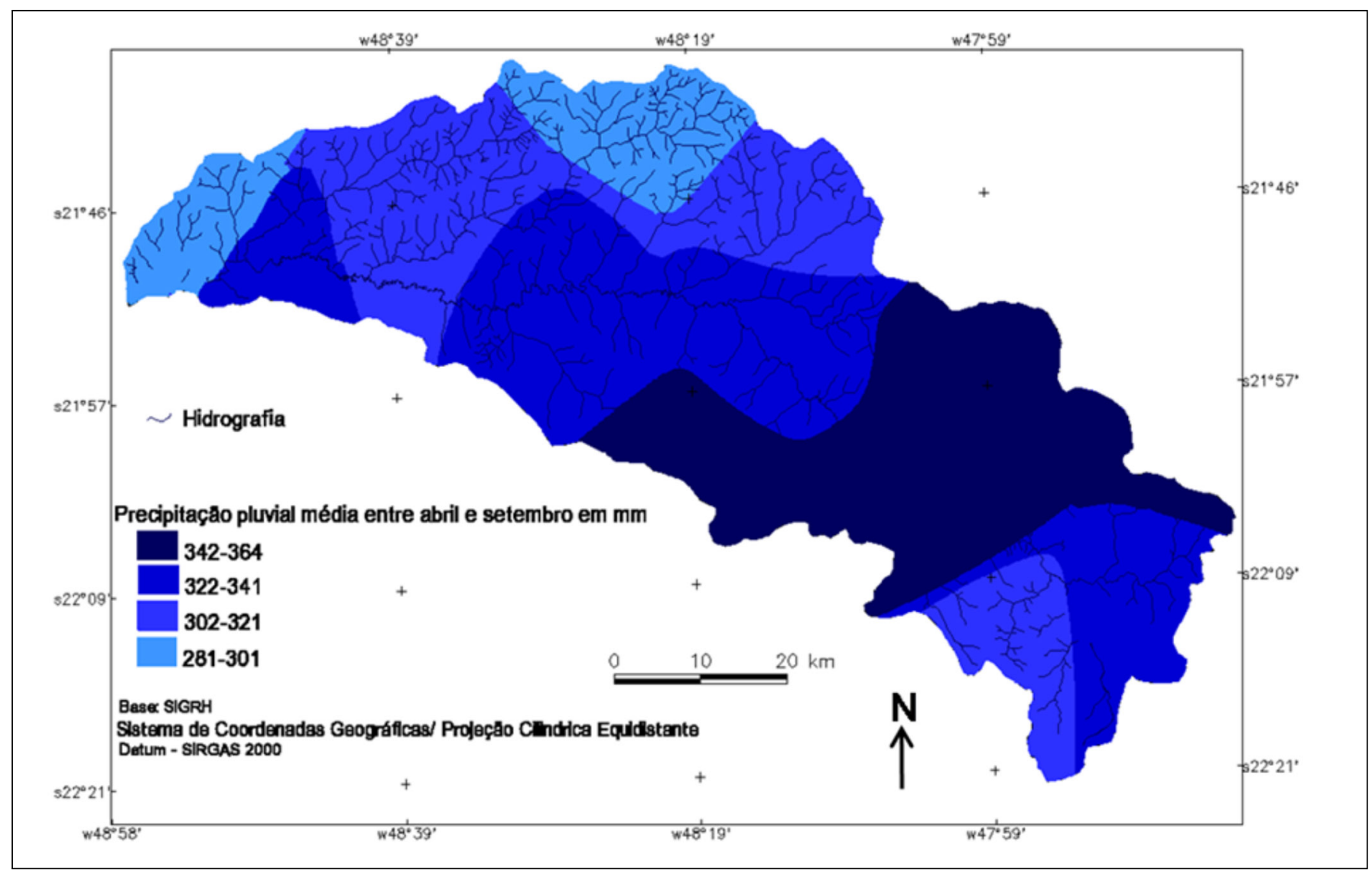

Figura 5 - Precipitação pluviométrica do período menos chuvoso na bacia hidrográfica.

A ocupação das classes em $\mathrm{km}^{2}$ e porcentagem desse período (menos chuvoso) na bacia do rio Jacaré Guaçú está representada na tabela 3 .

Tabela 3 - Área ocupada pelas classes de precipitação pluvial para o período menos chuvoso na bacia do rio Jacaré Guaçú.

\begin{tabular}{c|r|r}
\hline Categoria em mm & Área em $\mathrm{km}^{2}$ & Porcentagem (\%) \\
\hline $342-364$ & 1116,3 & 27,5 \\
\hline $322-341$ & 1448,3 & 35,8 \\
\hline $321-301$ & 1048,5 & 25,8 \\
\hline $281-301$ & 443,9 & 10,9 \\
\hline Total & 4057,0 & 100,0 \\
\hline
\end{tabular}

Os maiores valores, categorizados entre 342 e $364 \mathrm{~mm}$, ocupam 27,5\% (1116,2 $\left.\mathrm{km}^{2}\right)$ da área da bacia nos setores leste e parte do sul. A maior representatividade espacial $\left(1448,3 \mathrm{~km}^{2}-35,8 \%\right.$ da área) ocorre no intervalo 
compreendido entre 322 e 341 mm e ocupa áreas no baixo, médio e alto Jacaré Guaçú. A classe 321-301 mm ocorre nos setores sudeste, norte e oeste da bacia com ocupação de $1048,5 \mathrm{~km}^{2}$ (25,8\% do total). Os menores valores (281-301 $\mathrm{mm})$ aparecem no baixo jacaré Guaçú e apresentam a menor ocupação, ou seja, 443,9 km² (10,9\% do total da bacia hidrográfica).

Em relação a esse período (menos chuvoso), a média dos 16 postos é de $327,7 \mathrm{~mm}$. Neste caso, esses valores são representados pela categoria 322 e $341 \mathrm{~mm}$ cuja ocupação é a maior na bacia conforme citado.

A distribuição dos dados do período considerado chuvoso (outubro a março) é demonstrada na figura 6.

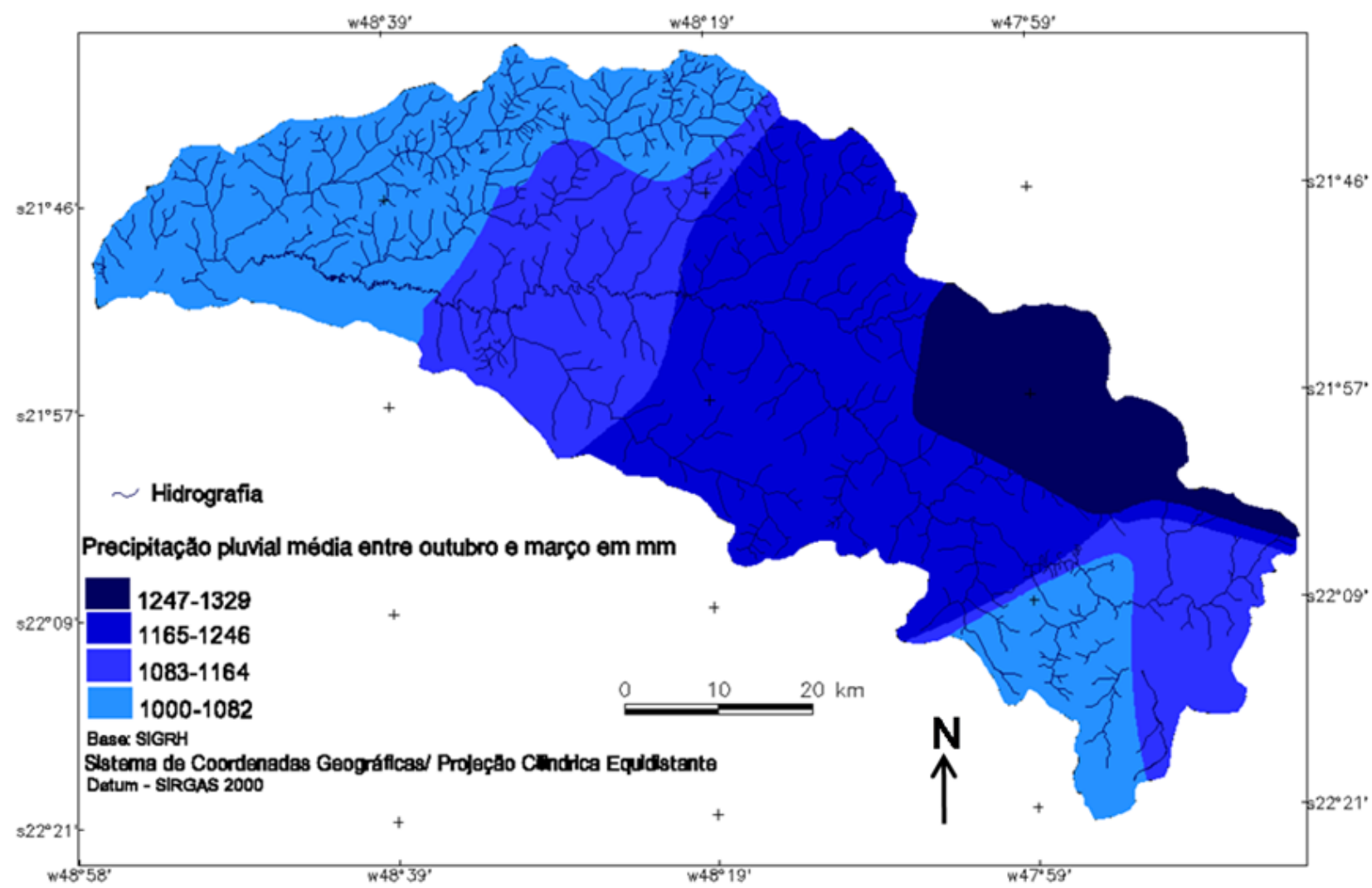

Figura 6 - Espacialização dos dados do período chuvoso na bacia do rio Jacaré Guaçú.

A área ocupada pelas classes do período chuvoso pode ser observada verificada na tabela 4.

Tabela 4 - Área ocupada pelas classes de precipitação pluvial para o período chuvoso na bacia do rio Jacaré Guaçú.

\begin{tabular}{c|r|r}
\hline Categoria em mm & Área em $\mathrm{km}^{2}$ & Porcentagem (\%) \\
\hline $1247-1329$ & 441,5 & 10,8 \\
\hline $1165-1246$ & 1360,7 & 33,6 \\
\hline $1083-1164$ & 971,8 & 23,9 \\
\hline $1000-1082$ & 1283,0 & 31,7 \\
\hline Total & 4057,0 & 100,0 \\
\hline
\end{tabular}

Em relação ao período chuvoso verifica-se que os maiores valores, dispostos entre 1247 e 1329 mm, ocorre no alto Jacaré Guaçú, setor leste da bacia com $441,5 \mathrm{~km}^{2}$ (10,8\% do total da bacia). A categoria 1165 - 1246 mm ocupa a maior área da bacia (1360,7 $\mathrm{km}^{2}-33,6 \%$ da área de estudo) e ocorre no médio e alto Jacaré Guaçú nos setor central, norte e sul da bacia hidrográfica. No oeste e sudeste da bacia hidrográfica, com representação de $23,9 \%\left(971,8 \mathrm{~km}^{2}\right)$, aparece a 
classe 1083-1164 mm enquanto que no baixo e alto Jacaré Guaçú (oeste e sudeste da área de estudo) ocorrem os menores valores, dispostos entre 1000 e $1082 \mathrm{~mm}$, com $1283 \mathrm{~km}^{2}$ de ocupação (31,7\% do total).

Para o período chuvoso a média dos valores dos postos é de 1141,9 mm que está disposto dentro da categoria 1083$1164 \mathrm{~mm}$ e representa $23,9 \%$ da área total da bacia hidrográfica do rio jacaré Guaçú.

A amplitude entre os valores médios dos postos é de $366,6 \mathrm{~mm}$ para a média anual, 70,8 $\mathrm{mm}$ para o período menos chuvoso e 291,4mm para o período chuvoso. Esses dados demonstram maior dinamismo da atmosfera no período chuvoso (outubro a março). Isso ocorre, sobretudo, em função da temperatura do ar mais elevada e da maior quantidade de umidade disposta na atmosfera nesse período ano que favorece aos processos convectivos para a formação de chuvas difusas na área de estudo.

\subsection{Variação topográfica e a precipitação pluvial}

A figura 7 exibe a variação topográfica e da precipitação pluvial média anual entre os pontos A e B na área de estudo.

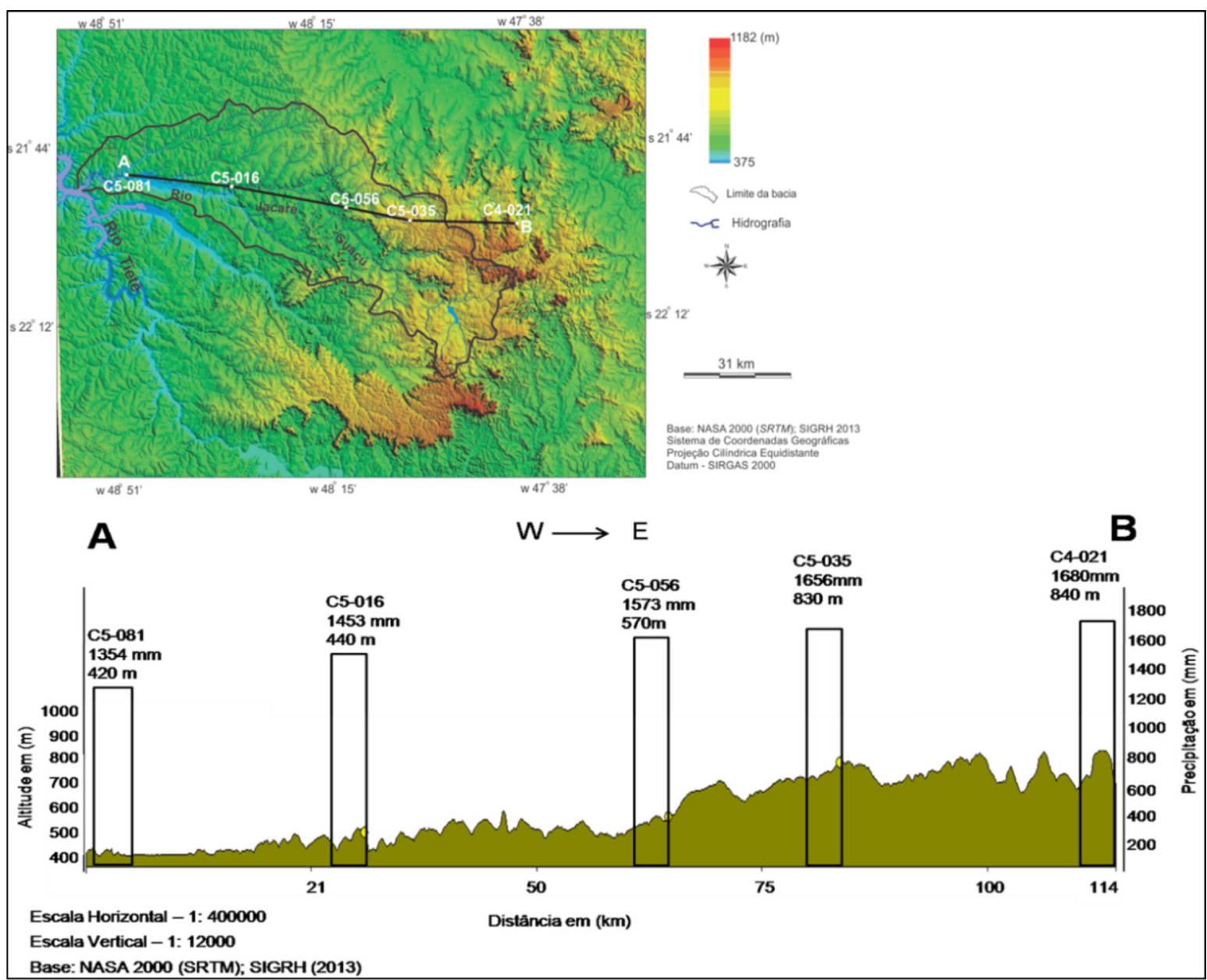

Figura 7 - Perfil topográfico AB com o histograma de precipitação plotado sobre a localização dos postos pluviométricos.

É possível verificar que entre o perfil definido $(\mathrm{AB})$, dispostos no sentido oeste para leste da bacia hidrográfica sobre os postos pluviométricos C5 - 081 e C4-021 e com distância aproximada de 114 km ocorre uma amplitude altimétrica $420 \mathrm{~m}$ e pluvial de $326 \mathrm{~mm}$. O gradiente de acréscimo pluviométrico nesse segmento é de aproximadamente 
0,8 mm a cada metro de elevação. Em termos morfoesculturais, o ponto A localiza-se sobre Planalto Centro Ocidental no baixo Jacaré Guaçú e o B sobre o Planalto Residual de São Carlos (ROSS, MOROZ, 1997).

Um perfil (CD) similar ao anterior em termos geomorfológicos, porém com valores altimétricos e sentido diferente (noroeste para o sudeste) pode ser observado a seguir (Figura 8).

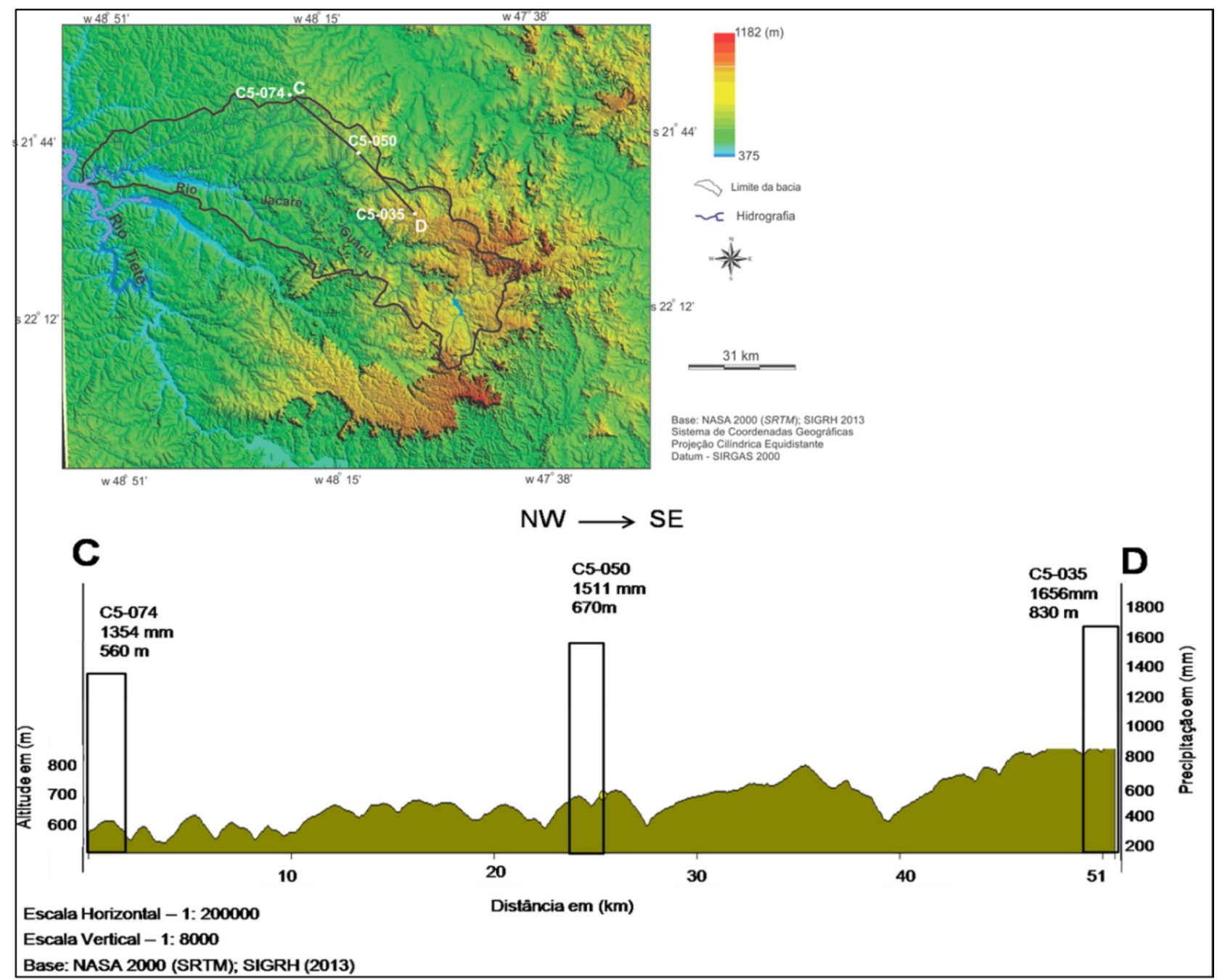

Figura 8 - Variação topográfica e pluvial no sentido noroeste sudeste (perfil CD) na bacia do rio Jacaré Guaçú.

Nesse segmento, onde a distância é de $51 \mathrm{~km}$, a precipitação varia de $1354 \mathrm{~mm}$ na altitude de $560 \mathrm{~m}$ (posto C5-081), $1511 \mathrm{~mm}$ com cota topográfica de $670 \mathrm{~m}$ no posto C5-050 a $1656 \mathrm{~mm}$ com altimetria de $830 \mathrm{~m}$ no posto C5-035. Nesse caso, a amplitude pluvial é de $302 \mathrm{~mm}$, a altimétrica $270 \mathrm{~m}$ e o gradiente de acréscimo pluviométrico é de aproximadamente $1,1 \mathrm{~mm}$ por metro de altitude.

O perfil EF, no sentido norte sul, na subunidade geomorfológica Planalto Centro Ocidental no médio Jacaré Guaçú pode ser observado na figura 9 . 


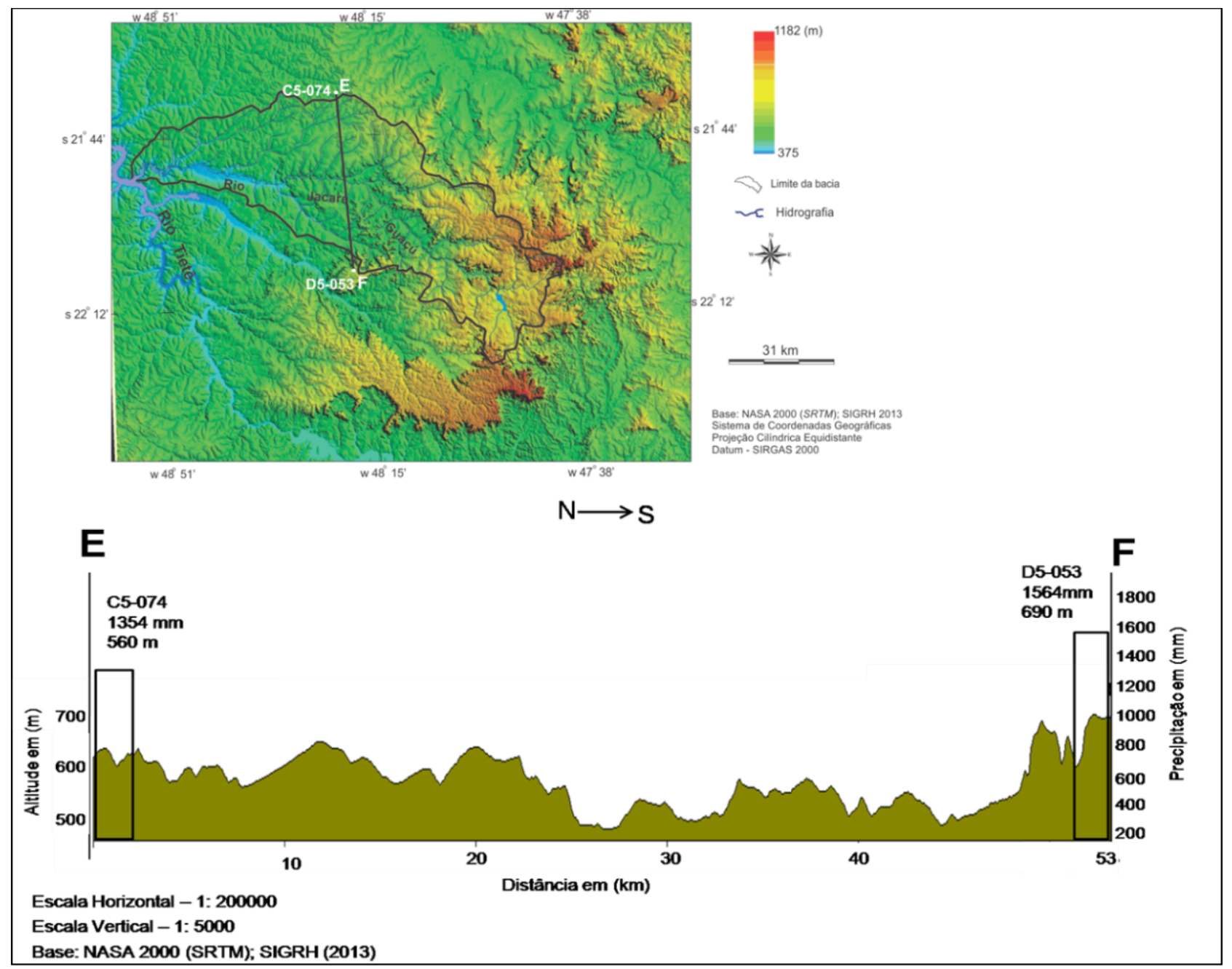

Figura 9 - Perfil topográfico EF com dados pluviais da área de estudo.

No contexto apresentado (EF), com amplitude topográfica de $130 \mathrm{~m}$ e distância de aproximadamente $53 \mathrm{~km}$ a pluviosidade varia entre $1354 \mathrm{~mm}$ (560 m de altitude) e $1564 \mathrm{~mm}$ a $690 \mathrm{~m}$ de altitude. Nesse transecto, a amplitude pluviométrica é de $210 \mathrm{~mm}$ e o gradiente de acréscimo é de aproximadamente $1,6 \mathrm{~mm}$ de chuva por metro de altitude.

Por meio dos transectos elaborados foi possível observar que o relevo demonstrou relevância sobre a variabilidade espacial das chuvas, sobretudo nos sentidos oeste para leste e noroeste para sudeste na área de estudo (baixo para o alto Jacaré Guaçú). De forma geral, pode se afirmar que fatores relacionados ao deslocamento de correntes de ar quente e úmida em função de sistemas de circulação local de ventos bem como a ascensão turbulenta do ar por meio da friç̧ão superficial podem favorecer a formação de nuvens e consequentemente de chuvas nas partes altas da bacia. O relevo também pode potencializar precipitações ciclônicas nas áreas mais elevadas (atuação de sistemas frontais no outono e inverno) e retardar seu deslocamento para as áreas relativamente mais baixas.

Correa (2013) na bacia do rio Piquiri no Estado do Paraná obteve uma amplitude de $200 \mathrm{~mm}$ entre as cotas de $420 \mathrm{~m}$ e $840 \mathrm{~m}$ de altitude. Para essas cotas altimétricas, na bacia do rio Jacaré Guaçú conforme demonstrado, a amplitude pluvial anual é de $326 \mathrm{~mm}$.

Os resultados confirmam a influência e a irregularidade do relevo no aumento da precipitação pluvial em áreas elevadas no Estado de São Paulo conforme demonstrado em Santanna Neto (1995) e Candido e Nunes (2008). 


\section{Considerações Finais}

Por meio dos dados obtidos é possível afirmar que a bacia do rio Jacaré Guaçú apresenta grande variabilidade espacial e temporal pluvial média anual e sazonal, conforme esperado para as áreas dispostas nos trópicos. A amplitude anual entre os dados dos postos analisados é de $366,6 \mathrm{~mm}$ e a sazonal é de $70,8 \mathrm{~mm}$ para o período menos chuvoso e 291,4mm para o período chuvoso.

Em relação à precipitação pluvial anual a maior representação espacial $(23,8 \%$ do total da área) ocorre no centro e sul da bacia hidrográfica com a categoria compreendida entre 1557 e $1617 \mathrm{~mm}$.

Para o período menos chuvoso o intervalo compreendido entre 322 e $341 \mathrm{~mm}$ foi o que apresentou maior ocupação, ou seja, 1448,2 $\mathrm{km}^{2}$ que corresponde a $35,7 \%$ da área de estudo.

No período considerado chuvoso, a maior representação espacial ocorre para a classe compreendida entre 1165 - 1246 mm cuja ocupação é de 33,6\% do total da área de estudo.

O relevo demonstrou exercer influência para a variabilidade de precipitações na bacia hidrográfica, sobretudo nos sentidos oeste para leste e noroeste para sudeste na área de estudo (baixo para o alto Jacaré Guaçú). Para a variação altimétrica disposta entre $420 \mathrm{~m}$ e 840 no sentido leste para oeste com distância aproximada de $114 \mathrm{~km}$ a amplitude pluvial foi de $326 \mathrm{~mm}$. No sentido noroeste para sudeste com distância de $51 \mathrm{~km}$ a amplitude pluvial obtida foi de 302 mm para uma variação topográfica disposta entre $670 \mathrm{~m}$ e $830 \mathrm{~m}$ de altitude (amplitude de $270 \mathrm{~m}$ ).

\section{Agradecimentos}

Ao Conselho Nacional de Desenvolvimento Científico e Tecnológico (CNPq) pela bolsa de estudo de acordo com o processo 141662/2013-1.

A CAPES e ao Programa de Cooperação Acadêmica, pelo financiamento de parte da pesquisa através do Processo 88887.124105/2014-00. Projeto “Análise integrada em bacias hidrográficas: estudos comparativos com distintos usos e ocupação do solo".

\section{Referências}

ANDRADE AR, NERY JT. Análise sazonal e espacial da precipitação pluvial na bacia hidrográfica do rio Ivaí Paraná. Boletim de Geografia. 2011;29(2):107-121.

BERTONI JC, TUCCI CEM. Precipitação. In: Tucci CEM. Hidrologia: ciência e aplicação. 2a ed. Porto Alegre: ABRH UFRGS; 2001. p.177-231.

CAMARA G, SOUZA RCM, FREITAS UM, GARRIDO J. SPRING: Interacting remote sensing and GIS by objectoriented data modelling. Computers \& Graphics. 1996:20(3): 395-403.

CÂNDIDO DH, NUNES LH. Influência da orografia na precipitação da área entre o vale do rio Tietê e a serra da Mantiqueira. GEOUSP - Espaço e Tempo. 2008:24:8-27.

CORREA, MGG. Distribuição espacial e variabilidade da precipitação pluviométrica na bacia do rio Piquiri-PR. [dissertation]. São Paulo: Faculdade de Filosofia, Letras e Ciências Humanas/USP; 2013. 102p.

CORREA MGG, GALVANI E. Análise estatística da variabilidade da precipitação pluviométrica para a bacia hidrográfica do rio Piquiri-PR. Boletim Paulista de Geografia. 2017:96:1-10. 
DATAGEO - SISTEMA AMBIENTAL PAULISTA. [Internet]. Infraestrutura de Dados Espaciais Ambientais do Estado de São Paulo. [cited 2016nov 16]. Available from: http://datageo.ambiente.sp.gov.br/.

GREGORY KJ, WALLING DE. Drainage basin form and processes: a Geomorphological aproach. 1st ed. New York: John Wiley \& Sons Ltda; 1973.

INSTITUTO BRASILEIRO DE GEOGRAFIA E ESTATÍSTICA - IBGE. Manual Técnico da Vegetação Brasileira. Rio de Janeiro: IBGE, 1992.

INSTITUTO BRASILEIRO DE GEOGRAFIA E ESTATÍSTICA - IBGE. Mapa de Clima do Brasil. Rio de Janeiro: IBGE, 2002.

MONTEIRO CAF. A dinâmica climática e as chuvas do estado de São Paulo: estudo em forma de atlas. 1st ed. São Paulo: USP/Igeo; 1973.

OLIVEIRA JB. Solos do Estado de São Paulo: descrição das classes registradas no mapa pedológico. 1st ed. Campinas: Instituto Agronômico/ Boletim Científico 45; 1999.

PINTO NLS, HOLTZ, ACT, MARTINS JA, GOMIDE, FLS. Hidrologia Básica. 15 st ed. São Paulo: Edgard Blücher; 2014.

PERROTA M. M., SALVADOR E. D., LOPES R. C., D’AGOSTINO L. Z., PERUFFO N, GOEMS S. D, et. al. Mapa Geológico do estado de São Paulo, escala 1:750000. 1st ed. São Paulo: CPRM; 2005.

ROSS J. L. S, MOROZ I. C. Mapa geomorfológico do Estado de São Paulo. Revista do Departamento de Geografia. 1996: 10:41-56.

SANTANNA NETO J. L.. As chuvas no Estado de São Paulo: contribuição ao estudo da variabilidade e tendência da pluviosidade na perspectiva da análise geográfica [thesis]. São Paulo: Faculdade de Filosofia, Letras, Artes e Ciências Humanas/USP;1995. 252 p.

SANTOS EHM, GRIEBELER NP, OLIVEIRALFC. Variabilidade espacial e temporal da precipitação pluvial na bacia hidrográfica do ribeirão João Leite - GO. Engenharia Agrícola. 2011:3(1):78-89.

SISTEMA INTEGRADO DE GERENCIAMENTO DE RECURSOS HÍDRICOS DO ESTADO DE SÃO PAULO [Internet]. Banco de dados Hidrológicos [cited 2013 feb 18]. Availablefrom: http://www.hidrologia.daee.sp.gov. br/.

SISTEMA INTEGRADO DE GERENCIAMENTO DE RECURSOS HÍDRICOS DO ESTADO DE SÃO PAULO [Internet]. Comitê da Bacia Hidrográfica do Tietê Jacaré. [cited 2017 jan 12]. Available from: http://www.sigrh. sp.gov.br/cbhtj/apresentacao.

UNITED STATE GEOLOGICAL SERVEY [Internet]. Earth Explorer. [cited 2016 mar 22]. Available from: http:// earthexplorer.usgs.gov/.

WORLD METEOROLOGICAL ORGANIZATION - WMO Guide to hydrological practices: data acquisition and processing, analysis, forecasting and other applications. 50st. Geneve: WMO; 1994.

ZANDONADI L, ACQUAOTTA F, FRATIANNI S, ZAVATTINI JA. Changes in precipitation extremes in Brazil (Paraná River Basin). Theoretical and Applied Climatology. 2015:119:01-18.

ZAVATINI JA, CANOH. Variações do ritmo pluvial na bacia do rio Corumbataí (SP). Boletim de Geografia Teorética. 1993:v.23(45):215-240. 